\title{
A comparative study of conceptual rainfall-runoff models GR4J, AWBM and Sacramento at catchments in the upper Godavari river basin, India
}

\author{
A Kunnath-PoovakKa and T I Eldho* \\ Department of Civil Engineering, Indian Institute of Technology Bombay, Mumbai 400 076, India. \\ *Corresponding author.e-mail: eldho@civil.iitb.ac.in
}

MS received 1 September 2017; revised 20 February 2018; accepted 4 May 2018; published online 25 January 2019

Accurate catchment level water resource assessment is the base for integrated river basin management. Due to the complexity in model structure and requirement of a large amount of input data for semi-distributed/distributed models, the conceptual models are gaining much attention in catchment modelling these days. The present study compares the performance of three conceptual models, namely GR4J, Australian Water Balance Model (AWBM) and Sacramento for runoff simulation. Four small catchments and one medium catchment in the upper Godavari river basin are selected for this study. Gap-filled daily rainfall data and potential evapotranspiration (PET) measured from the same catchment or adjacent location are the major inputs to these models. These models are calibrated using daily Nash-Sutcliffe efficiency (NSE) with bias penalty as the objective function. GR4J, AWBM and Sacramento models have four, eight and twenty-two parameters, respectively, to optimise during the calibration. Various statistical measures such as NSE, the coefficient of determination, bias and linear correlation coefficient are computed to evaluate the efficacy of model runoff predictions. From the obtained results, it is found that all the models provide satisfactory results at the selected catchments in this study. However, it is found that the performance of GR4J model is more appropriate in terms of prediction and computational efficiency compared to AWBM and Sacramento models.

Keywords. Rainfall-runoff model; GR4J; AWBM; Sacramento; Source; calibration.

\section{Introduction}

Hydrologic models have been widely used for assessing the impact of climate and land-use change on water budget and for predicting extreme events such as flood and drought (Green et al. 2006; Sorooshian et al. 2008; Pechlivanidis et al. 2011; Fowler et al. 2016). The complexity of hydrologic models varies from simple empirical models to complex process-oriented mathematical models. With the development of technology and computing systems, complex catchment models that can include distributed information about catchment such as land use, soil properties, etc., have been developed. These distributed models predict state variables as local averages, by dividing the catchment into grid cells or small units. Distributed models are capable of presenting the spatial variability of processes, boundary conditions and parameters to some extent. However, in an 
operational context, these models are limited due to high data requirement and computational time.

Despite these distributed models, lumped models, which generally require very fewer inputs, simulate streamflow in response to precipitation, empirically or conceptually, with acceptable accuracy (Chiew et al. 2002; Croke et al. 2006). Generally, lumped models have differential and empirical equations representing different hydrologic processes in rainfall-runoff modelling. It does not consider the spatial variability of topography, land use and inputs. Regardless of their lumped nature, these models help water engineers and hydrologists in reservoir management (Yang et al. 1995), flood and drought forecasting (Yang and Michel 2000) and flood frequency assessment (Cameron et al. 1999) as given in many case studies in the literature. However, these models have limited capability to predict streamflow changes with respect to land-use changes (Lavabre et al. 1993; Lørup et al. 1998).

The choice of right models for hydrologic assessment is one of the crucial phases of modelling practices. The modelling interfaces, which gather all the information about catchment and different rainfall-runoff models in one platform, are used commonly these days for hydrological studies (Rassam et al. 2011; Carr and Podger 2012; Dutta et al. 2012; Mannik et al. 2012). The Source modelling platform developed by eWater limited, Australia, is one such example. The Source is a modelling interface developed for addressing many water management issues. The Source mainly has three modes of operation such as catchment mode, river operational mode and river management mode as used in past studies (Carr and Podger 2012; Dutta et al. 2012). The Source framework includes about 11 rainfall-runoff models, among which GR4J, Australian Water Balance Model (AWBM) and Sacramento are adopted for the present study.

The GR4J (Edijatno et al. 1999) is a four-parameter daily lumped conceptual rainfallrunoff model, which is proven to be more effective than complex conceptual models such as TOPMODEL, IHACRES, etc. (Perrin et al. 2003). The GR4J model is the modified version of the threeparameter model GR3J developed by Edijatno (1989). The AWBM was developed by Boughton (2004). This model is a lumped conceptual model primarily developed for river basin management in Australia. The Sacramento model was originally developed for the United States National Weather Service and State of California, Department of Water Resources by Burnash et al. (1973). Compared to GR4J and AWBM, Sacramento is a complex model with 22 parameters and 5 water stores.

The Godavari river basin in India is the second largest river basin after the Ganges. Many farmers and industries are depending on this river for irrigation and other purposes. The river basin includes many reservoirs and irrigation projects. Due to these reasons, integrated management of water in this basin is very important. Most of the river basins in India are heterogeneous in terms of land use, topography, climatology, etc. Therefore, distributed models such as SWAT (Soil Water Assessment Tool), Variable Infiltration Capacity (VIC) model, etc., are being used in these catchments for hydrologic modelling (Gosain et al. 2006, 2011; Prabhanjan et al. 2014; Narsimlu et al. 2015; Hengade et al. 2017; Madhusoodhanan et al. 2017). However, hydrologic modelling experiments with these models are limited by the lack of ground data for model simulations (Refsgaard 1997). As discussed above, the conceptual lumped models require a very limited number of inputs for generating stream discharge in comparison with distributed models. Nonetheless, very limited numbers of studies are reported with the use of lumped models in Indian river basins. Thus, in this study, we have attempted to understand the capability of lumped models such as GR4J, AWBM and Sacramento in diversified Godavari river basin catchments. Potential evapotranspiration (PET) and rainfall are the major inputs to these models. The key objectives of the present study include: (i) compare the efficacy of the selected lumped rainfall-runoff models in Source platform; (ii) find the best lumped model for catchments in the upper Godavari basin; and (iii) discuss the advantages and limitations of models used in this study.

\section{Methodology}

\subsection{Study area}

The Godavari river basin is India's second largest river basin after the Ganges in length, area and water abundance. It flows towards the Bay of Bengal predominantly through seven Indian states (Maharashtra, Telangana, Andhra Pradesh, Karnataka, Madhya Pradesh, Chhattisgarh and Orissa) 


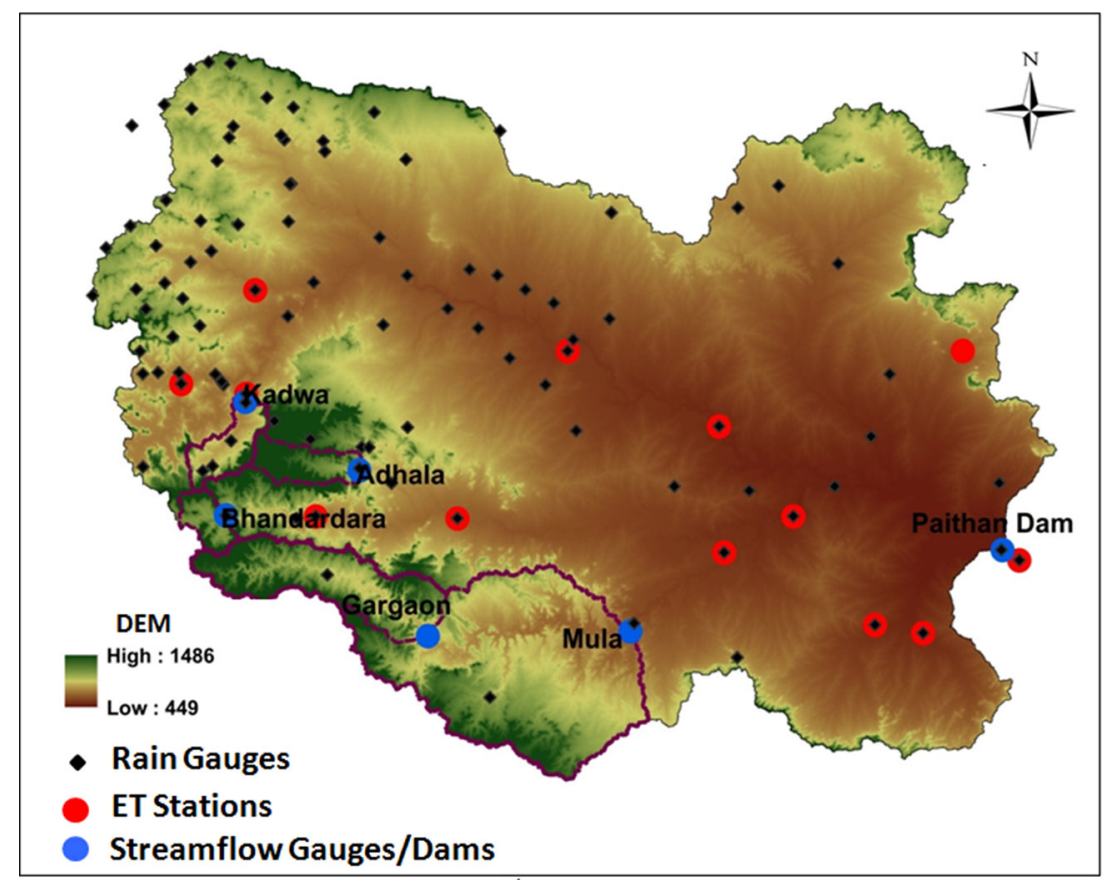

Figure 1. DEM of the upper Godavari basin with study catchments, ET stations and streamflow gauges/dams highlighted.

Table 1. Summary of the study catchments.

\begin{tabular}{|c|c|c|c|c|c|}
\hline Catchments & $\begin{array}{c}\text { Area } \\
\left(\mathrm{km}^{2}\right)\end{array}$ & $\begin{array}{c}\text { Min/Max } \\
\text { elevation } \\
\quad(\mathrm{m})\end{array}$ & Major land use & $\begin{array}{c}\text { Calibration } \\
\text { period }\end{array}$ & $\begin{array}{l}\text { Validation } \\
\text { period }\end{array}$ \\
\hline Adhala & 134 & $660 / 1358$ & Barren land, agriculture land & 1995-2009 & $2010-2013$ \\
\hline Bhandardara & 98 & $747 / 1646$ & Agriculture land, forest & 1995-2009 & 2010-2013 \\
\hline Gargaon & 616 & $616 / 1459$ & Agriculture land, forest & 2000-2004 & $2004-2005$ \\
\hline Kadwa & 162 & $578 / 1486$ & Agriculture land & $2001-2010$ & $2011-2014$ \\
\hline Mula & 2300 & $515 / 1460$ & Agriculture land, barren land & 1995-2009 & 2010-2013 \\
\hline
\end{tabular}

and Pondicherry (Yanam) (Hengade and Eldho 2016). In this study, we are comparing the various hydrological models in the upper Godavari basin which lies entirely in Maharashtra state (figure 1). The catchment area, which contributes to the Godavari river up to Paithan dam or Jayakwadi reservoir is referred to as upper Godavari river basin. The geographical extent of the area is $21,048 \mathrm{~km}^{2}$ spreading from longitude $73^{\circ} 29^{\prime} 30$ to $75^{\circ} 29^{\prime} 6^{\prime \prime} \mathrm{E}$ and from latitude $19^{\circ} 2^{\prime} 25^{\prime \prime}$ to $20^{\circ} 24^{\prime}$ $58^{\prime \prime} \mathrm{N}$. The elevation of the upper Godavari basin varies from 449 to $1486 \mathrm{~m}$ sloping from Western Ghats to east (figure 1).

The south-west monsoon prevails over the basin during the months of June to September and the Godavari basin receives $85 \%$ of its annual rainfall during this season. The annual rainfall depth across the basin varies from 600 to $3000 \mathrm{~mm} / \mathrm{yr}$. Water resources of the upper Godavari basin are mainly used for irrigation. Many low head dams are constructed in this basin for diverting water for irrigation purposes. A big project such as Gangapur was also constructed to supply drinking water to nearby towns.

For this study, four small catchments (namely Adhala, Bhandardara, Gargaon and Kadwa) and one medium catchment (Mula) with good streamflow record in the upper Godavari basin are selected to perform the calibration experiments (figure 1). All the catchments are upstream unregulated catchments without any storage structures such as dams or reservoirs. The details of the selected catchments are given in table 1 . 


\subsection{Source model}

The Source is a modelling platform developed by eWater, Australia, for both catchment and river basin modelling (https://wiki.ewater.org.au). The structure of the model is flexible for both simple and complex water management problems. The Source modelling comprises four steps: model building, calibration, running the model and finally preparation of the report (Dutta et al. 2012; eWater Australia 2017). The Source platform is best used for developing river operational models (helps water authorities to optimise day-today operations), river system models (helps to understand the impacts of water resource policy on system storages, flows and water shares), catchment models (helps to model water quality constituents) and urban models (helps to optimise the urban supply systems) (Carr and Podger 2012).

Since the aim of the current study is to analyse the efficacy of the rainfall-runoff models available in the Source platform for catchments in the upper Godavari river basin, the calibration experiments were performed in catchment mode. The catchment mode helps to model the catchment management processes such as downstream flow, upstream flow, total flow, etc. Catchment scenarios are usually developed with 'Geographic Wizard for catchments' in the Source, which include the systematic procedure to proceed. The Source catchment mode includes a conceptual rainfall-runoff modelling framework for estimating catchment water yield and runoff characteristics (Dutta et al. 2012) using models such as AWBM (Boughton 2004), GR4J (Edijatno et al. 1999; Perrin et al. 2003) and Sacramento (Burnash et al. 1973). These models are configured within the framework to allow the user to run the rainfall-runoff models mainly at a lumped scale with lumped input for the catchments. In the Source, catchments can be delineated into subcatchments with spatially explicit inputs with lumped outputs. These models can be calibrated using an observed discharge in the gauged catchments using available objective functions and optimisation methods in the Source framework (https://wiki.ewater.org. au).

In this study, we tested the efficacy of AWBM, GR4J and Sacramento models in the Source rainfall-runoff framework. A detailed description of these models is given in the following sections.

\section{$2.2 .1 \mathrm{GR} 4 J$}

The GR4J model is one of the simplest lumped hydrological models. GR4J has two water stores (production and routing) and has only four parameters to optimise during the calibration (Perrin et al. 2003). They are given in table 2 .

The two inputs to the model are daily rainfall $(P)$ and evapotranspiration $(E T)$. The schematic diagram of GR4J model is given in figure 2. At first, the model neutralises $P$ by ET to determine the net rainfall $P_{n}$ and net evapotranspiration $E T_{n}$ (Perrin et al. 2003), calculated by:

if $P>E T$, then

$$
P_{n}=P-E T \text { and } E T_{n}=0 .
$$

If $P<E T$, then

$$
P_{n}=0 \quad \text { and } \quad E T_{n}=E T-P .
$$

The net rainfall is distributed to storage $\left(P_{s}\right)$ and surface runoff $\left(P_{n}-P_{s}\right)$ (figure 2). $P_{s}$ goes to production store and drains as ET from the storage and percolation. This percolation and the $P_{n}-P_{s}$ form the total runoff, which is then divided into two parts. Ninety percent of it is routed by the unit hydrograph one (UH1) and routing store. The remaining $10 \%$ of runoff is routed by UH2. The length of UH2 is twice the length of UH1.

\subsubsection{Australian Water Balance Model}

The AWBM is a simple catchment water balance model with three surface storages to simulate partial area of runoff, a baseflow store and a surface runoff routing store. The water balance for AWBM surface partial areas $(A 1, A 2, A 3)$ are calculated separately, each store has its own storage capacities $(C 1, C 2, C 3)$ (Boughton 2004). $A 1, A 2$ and $A 3$ represent the user-defined land use or soil classification as proportions of the area of the catchment. Thus, the sum of $A 1, A 2$ and $A 3$ must be 1 (https://wiki.ewater.org.au). The schematic diagram of AWBM is shown in figure 2. The AWBM model has eight parameters as shown in table 2 .

At each time step of the model, rainfall is added to surface storages and the evaporation is subtracted from each store separately. Daily rainfall spills are becoming excess rainfall. This excess rainfall is shared between baseflow store and surface routing store. The parameter baseflow index determines the amount of water to be transferred to each 
Table 2. Parameters of GR4J, AWBM and Sacramento models.

\begin{tabular}{|c|c|c|c|c|}
\hline Parameter & Description & Units & Min & Max \\
\hline \multicolumn{5}{|c|}{ GR4J model } \\
\hline$X 1$ & Maximum capacity of the production store & $\mathrm{mm}$ & 1 & 1500 \\
\hline$X 2$ & Water exchange coefficient for the catchment & $\mathrm{mm}$ & -10 & 5 \\
\hline$X 3$ & $\begin{array}{l}\text { One-day maximum capacity of the routing } \\
\text { store }\end{array}$ & $\mathrm{mm}$ & 1 & 500 \\
\hline$X 4$ & Time-base of the unit hydrograph & Days & 0.5 & 4 \\
\hline \multicolumn{5}{|c|}{ AWBM model } \\
\hline KS & Surface flow recession constant & & 0 & 1 \\
\hline$K$ & Base flow recession constant & & 0 & 1 \\
\hline$C 1$ & Capacity of surface store 1 & $\mathrm{~mm}$ & 0 & 50 \\
\hline$C 2$ & Capacity of surface store 2 & $\mathrm{~mm}$ & 0 & 200 \\
\hline$C 3$ & Capacity of surface store 3 & $\mathrm{~mm}$ & 0 & 500 \\
\hline BFI & Base flow index & & 0 & 1 \\
\hline$A 1$ & Partial area of surface store 2 & & 0 & 1 \\
\hline$A 2$ & Partial area of surface store 1 & & 0 & 1 \\
\hline \multicolumn{5}{|c|}{ Sacramento model } \\
\hline LZPK & Ratio of water in LZFPM & Fraction & 0.001 & 0.015 \\
\hline LZSK & Ratio of water in LZFSM & Fraction & 0.03 & 0.2 \\
\hline UZK & Fraction of water in UZFWM & Fraction & 0.2 & 0.5 \\
\hline UZTWM & Upper zone tension water maximum & $\mathrm{mm}$ & 25 & 125 \\
\hline UZFWM & Upper zone free water maximum & $\mathrm{mm}$ & 10 & 75 \\
\hline LZTWM & Lower zone tension water maximum & $\mathrm{mm}$ & 75 & 300 \\
\hline LZFSM & Lower zone free water supplemental maximum & $\mathrm{mm}$ & 15 & 300 \\
\hline LZFPM & Lower zone free water primary maximum & $\mathrm{mm}$ & 40 & 600 \\
\hline PFREE & $\begin{array}{l}\text { The minimum proportion of percolation from } \\
\text { the upper zone to the lower zone directly avail- } \\
\text { able for recharging the lower zone free water } \\
\text { stores }\end{array}$ & Percent/100 & 0 & 0.5 \\
\hline REXP & $\begin{array}{l}\text { An exponent determining the change of the } \\
\text { percolation rate with changing lower zone } \\
\text { water storage }\end{array}$ & None & 0 & 3 \\
\hline ZPERC & $\begin{array}{l}\text { Parameter defining the maximum percolation } \\
\text { rate }\end{array}$ & None & 0 & 80 \\
\hline SIDE & $\begin{array}{l}\text { Ratio between non-channel baseflow and chan- } \\
\text { nel baseflow }\end{array}$ & Ratio & 0 & 0.8 \\
\hline SSOUT & $\begin{array}{l}\text { Channel loss through the porous material in } \\
\text { the bed of the stream }\end{array}$ & $\mathrm{mm}$ & 0 & 0.1 \\
\hline PCTIM & Permanently impervious fraction of the basin & Percent/100 & 0 & 0.05 \\
\hline ADIMP & $\begin{array}{l}\text { Fraction of the catchment, which is impervious } \\
\text { under soil saturation conditions }\end{array}$ & Percent/100 & 0 & 0.2 \\
\hline SARVA & $\begin{array}{l}\text { A decimal fraction of the basin, which can } \\
\text { deplete stream flow by evapotranspiration }\end{array}$ & Percent/100 & 0 & 0.1 \\
\hline RSERV & $\begin{array}{l}\text { Fraction of lower zone free water unavailable } \\
\text { for transpiration }\end{array}$ & Percent/100 & 0 & 0.4 \\
\hline UH1 & First component of the unit hydrograph & Percent/100 & 0 & 1 \\
\hline $\mathrm{UH} 2$ & Second component of the unit hydrograph & Percent/100 & 0 & 1 \\
\hline UH3 & Third component of the unit hydrograph & Percent/100 & 0 & 1 \\
\hline UH4 & Fourth component of the unit hydrograph & Percent/100 & 0 & 1 \\
\hline UH5 & Fifth component of the unit hydrograph & Percent/100 & 0 & 1 \\
\hline
\end{tabular}




\section{(b) $\underline{\text { AWBM }}$}

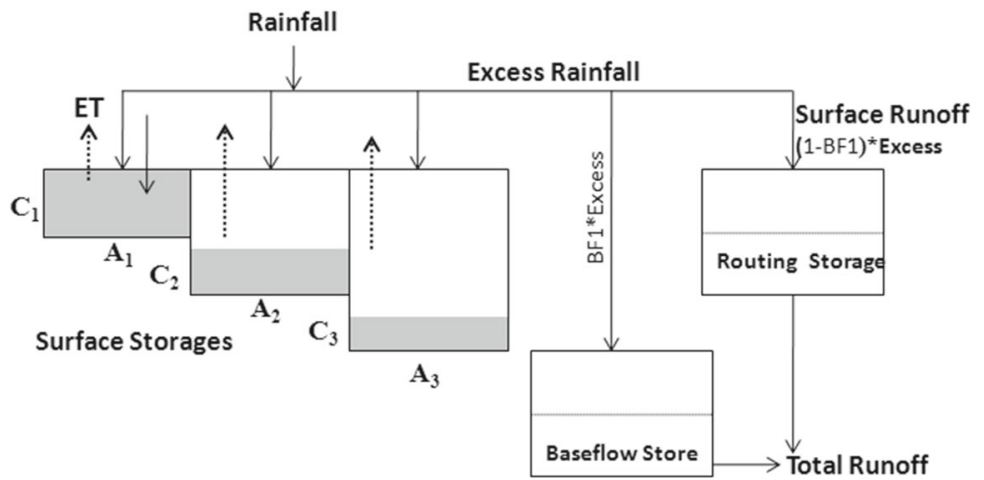

(c) Sacramento

Rainfall

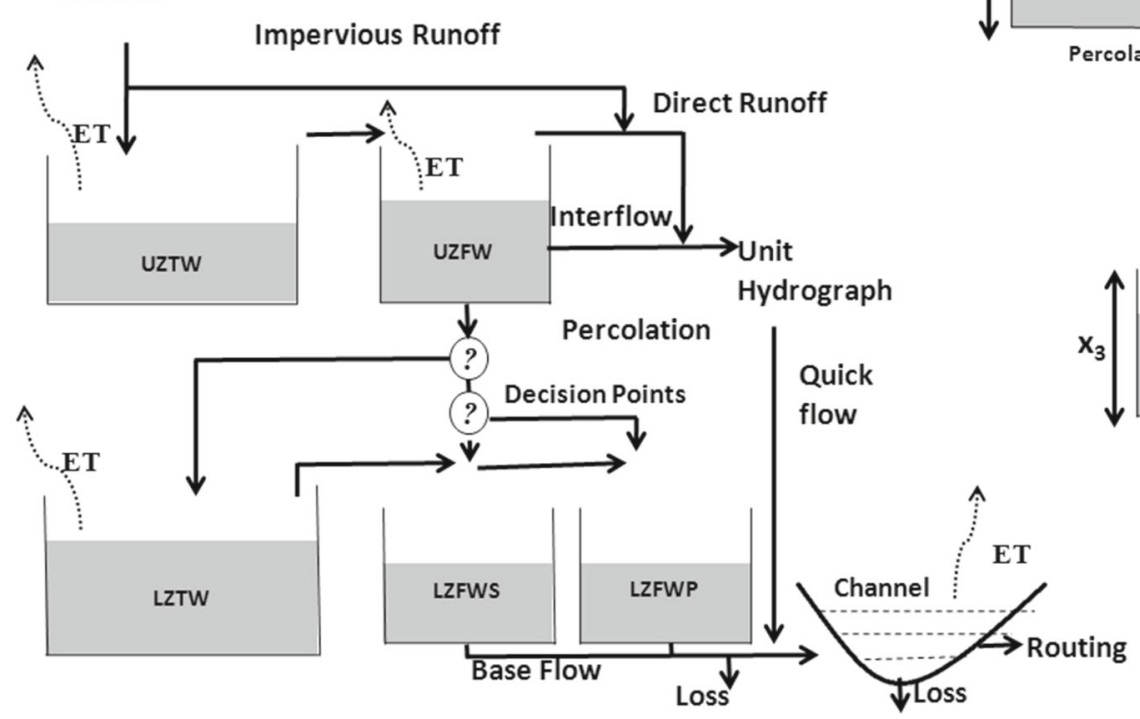

(a) $\underline{\text { GR4J }}$
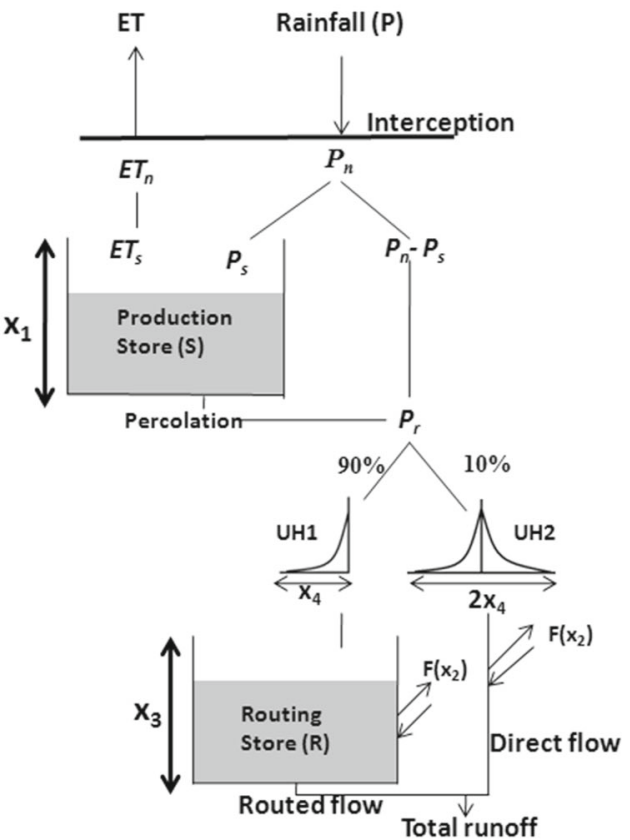

Figure 2. The schematic diagram of (a) GR4J (modified from Perrin et al. 2003), (b) AWBM (modified from Boughton 2004) and (c) Sacramento (modified from Ajami et al. 2004) models.

store. The total runoff is the sum of surface runoff and baseflow (Jones et al. 2006).

\subsubsection{Sacramento}

Sacramento is a complex model compared to other two models, and uses daily rainfall and PET to estimate the daily runoff. Sacramento has 5 stores and 22 parameters (table 2 ). Sacramento represents the hydrologically active zone of the soil conceptually as two layers, a thin upper layer and a much thicker lower layer. Each layer consists of tension and free water storages that interact to generate soil moisture states and five components of runoff (Burnash et al. 1973; Bumash 1995; Anderson et al. 2006). The schematic diagram of Sacramento is shown in figure 2 .
There are five stores in the Sacramento model:

(1) upper zone tension water (UZTW);

(2) upper zone free water (UZFW);

(3) lower zone tension water (LZTW);

(4) lower zone primary free water (LZFWP); and

(5) lower zone supplementary free water (LZFWS).

In tension water stores, water is stored between the soil profile by surface tension and water is removed from this layer only through evapotranspiration. In free water store, water can move vertically and laterally through the soil, and can be released as interflow (upper zone) or baseflow (lower zone). The Sacramento model divides the catchment into impervious and pervious areas. Generally, lakes, rivers, pavement and other impervious surfaces, which directly linked to the stream network, cover 
the impervious area. The impervious area produces runoff for any rainfall while the pervious area only produces runoff during heavy rainfall (https://wiki.ewater.org.au).

Streamflow prediction from Sacramento is the aggregate impervious runoff from permanent impervious areas and variable impervious areas, surface runoff, interflow and baseflow. Impervious runoff, direct runoff and surface runoff are occurring in the same time interval as the rain, with no time delay, generating the runoff component. Time delay for interflow is in days, supplemental baseflow has a delay of weeks or months and primary baseflow has a delay of months or years (https://wiki.ewater.org.au).

\subsection{Data}

Rainfall and PET are the two major inputs to the selected models. Rainfall data was available for 102 rain gauges (figure 2) in the upper Godavari basin for a period of 1985-2015. The rainfall data records with missing data were infilled with data from other well-correlated gauges at a minimum distance. Using these rainfall records, eWater, Australia, has generated the rainfall data for each subcatchment in the upper Godavari basin using the Theissen polygon weighted rainfall method (Şen 1998). The Theissen polygons were drawn for all 102 rain gauge stations and rainfall data from the polygons intersecting each subcatchment were used to represent the subcatchment rainfall (Redpath and Daamen 2018). The observed pan evaporation data was used as a surrogate of PET in this study. The pan evaporation data was available from 13 stations in the upper Godavari basin as shown in figure 1. Therefore, the PET data for each catchment was calculated by summing up the pan evaporation data from adjacent stations by giving equal weight. If the pan evaporation data from those stations is for the very short period, the daily mean value of PET was calculated for each day in a year for the available period and copied for the entire calibration period. Daily observed runoff data is available for all the selected catchments for at least 6 yrs during 1985-2013.

\subsection{Model calibration}

There are mainly two steps for calibrating a hydrologic model in the source platform (https:// wiki.ewater.org.au). They are model building and calibration. The procedure is similar for all the rainfall-runoff models in the Source platform.

In model building, a geographic model is built for a selected catchment using the digital elevation model (DEM) of the catchment in the Source using 'create new project' wizard. Further, we have to assign climate inputs to rainfall-runoff models. The rainfall-runoff model configuration dialogue box provides default parameters or likely ranges for the chosen rainfall-runoff model. In the Source, there is an option for defining the functional units within the catchment. Functional units represent areas within sub-catchments that behave in functionally similar ways. In the present study, the functional unit is just one.

Combination of Shuffled Complex Evolution (SCE) and Rosenbrock optimisation was used to calibrate each model. No land use land cover data was used to define the functional units in the catchment. Each catchment was considered as one unit. Calibration and validation period chosen for each catchment is given in table 1 . The input observations should be on daily scale to inform Source rainfall-runoff models. The objective function considered for calibrating the model was daily Nash-Sutcliffe efficiency (NSE) with bias penalty. Bias penalty represents the log transformation of the absolute value of relative bias between observations and simulations (Viney et al. 2009). Bias penalty is included in the calibration of rainfallrunoff models in the Source framework along with NSE to counteract biased solutions.

\subsection{Model evaluation}

The consistency, adaptability, performance and accuracy of the model must be evaluated. NSE, percent bias (PBIAS) and linear correlation coefficient $(R)$ have been used as the efficiency criteria to evaluate the performance of models in this study.

The Nash-Sutcliffe model efficiency is used to test the predictive power of hydrological models. The NSE has a range between $-\infty$ and 1 . When NSE is equal to 1 , it indicates a perfect match of estimated discharge with the observed data, whereas an efficiency of 0 suggests that the predictions of the model are as accurate as the observed data's mean. While an efficiency, which is less than zero (NSE $<0$ ), corresponds that the observed mean is better than model predictions (Nash and Sutcliffe 1970): 


$$
\mathrm{NSE}=1-\frac{\sum_{i=1}^{n}\left(Q_{o i}-Q_{s i}\right)^{2}}{\sum_{i=1}^{n}\left(Q_{o i}-Q_{o m}\right)^{2}},
$$

where $Q_{o i}$ is the observed discharge, $Q_{s i}$ is the simulated discharge and $Q_{o m}$ is the mean observed discharge.

PBIAS calculates the percentage of simulations above or below the observations. The optimal value for PBIAS is zero and the low magnitude represents the accurate model simulation. The positive value of PBIAS indicates an underestimation of simulations and negative values represent the overestimation of simulations (Gupta et al. 1999). It is calculated using the following equation:

$$
\text { PBIAS }=\frac{\sum_{i=1}^{n} Q_{o i}-Q_{s i}}{\sum_{n=1}^{i} Q_{o i}} * 100 .
$$

Pearson's correlation coefficient, commonly known as the linear correlation coefficient $(R)$, estimates the linear relationship between the observations and simulations. The value of $R$ ranges from -1 to $1, R=0$ is a symbol of no relationship and -1 indicates the inverse relationship (Moriasi et al. 2007):

$$
R_{\left(Q_{o}, Q_{s}\right)}=\frac{\operatorname{cov}\left(Q_{o}, Q_{s}\right)}{\sigma_{o} \sigma_{s}},
$$

where $\sigma_{o}$ and $\sigma_{s}$ are the standard deviations of observations and simulations.

Model predictions are evaluated graphically as well, using the time series plot, cumulative distribution of streamflow as well as the exceedance probability curve. Monthly time series plots are drawn as the daily time series plots and are difficult to interpret.

\section{Model results}

All the models GR4J, AWBM and Sacramento have been calibrated in all the selected catchments in the upper Godavari basin using the Flow Calibration Wizard in Source 4.1.0. The optimisation method used was SCE with Rosenbrock algorithm and the objective function chosen was NSE daily with bias penalty. Daily calibration was performed in all cases. The efficacy of models GR4J, AWBM and Sacramento was compared by calculating the statistical measures such as daily NSE, PBIAS and correlation coefficient of simulated streamflow. It was also analysed by plotting event-based streamflow, an exceedance probability curve and cumulative streamflow diagram.

Figure 3 compares the NSE of streamflow obtained for GR4J, AWBM and Sacramento models for both calibration and validation period in all the study catchments. For all the catchments, NSE was close to or greater than 0.5 in both calibration and validation period. From the figure, it is clear that GR4J is either better or performing similar to AWBM or Sacramento in both calibration and validation period. During the validation, GR4J provided slightly better NSE than AWBM and Sacramento for all the catchments except Adhala and was above 0.5 in all cases. The monthly NSE for GR4J model was around 0.8 for most of the cases.

PBIAS, which is the percentage deviation of simulations from the observations, is given in figure 4 for both calibration and validation period. Best results are obtained when PBIAS is zero (Moriasi et al. 2007). Compared to other two models, GR4J was giving good results with PBIAS less than $\pm 5 \%$ in the calibration period. Positive values of PBIAS in the calibration period indicate the underestimation of streamflow by the models. The high values of PBIAS $(+60 \%)$ by AWBM and Sacramento in Bhandardara and Gargaon catchment were due to the inability of these models to capture peak flow (figure 6). Nonetheless, the high value of parameter $x_{2}$, which controls the baseflow component of the GR4J model, improves the peak flow in Bhandardara and Gargaon. However, due to high $x_{2}$, streamflow predictions at Bhandardara were affected adversely by increased low flows. During the validation, AWBM performs slightly better than GR4J in the catchments Kadwa and Mula in terms of PBIAS.

$R$ illustrates the linear relationship between the observations and simulations. A value greater than 0.5 is advised as the good fit (Moriasi et al. 2007). In the present study, all the models provided $R$ greater or equal to 0.7 for both calibration and validation period (figure 5 ). The $R$ value given by each model at every catchment was almost the same. From the numerical analysis performed, it is concluded that all models are giving satisfactory results with GR4J performing marginally better.

Graphical techniques are used to visually interpret the predictive capacity of the models. In this study, monthly time series plots for streamflow were drawn for each catchment for a better understanding of the results. The daily predictions were converted into monthly values and 


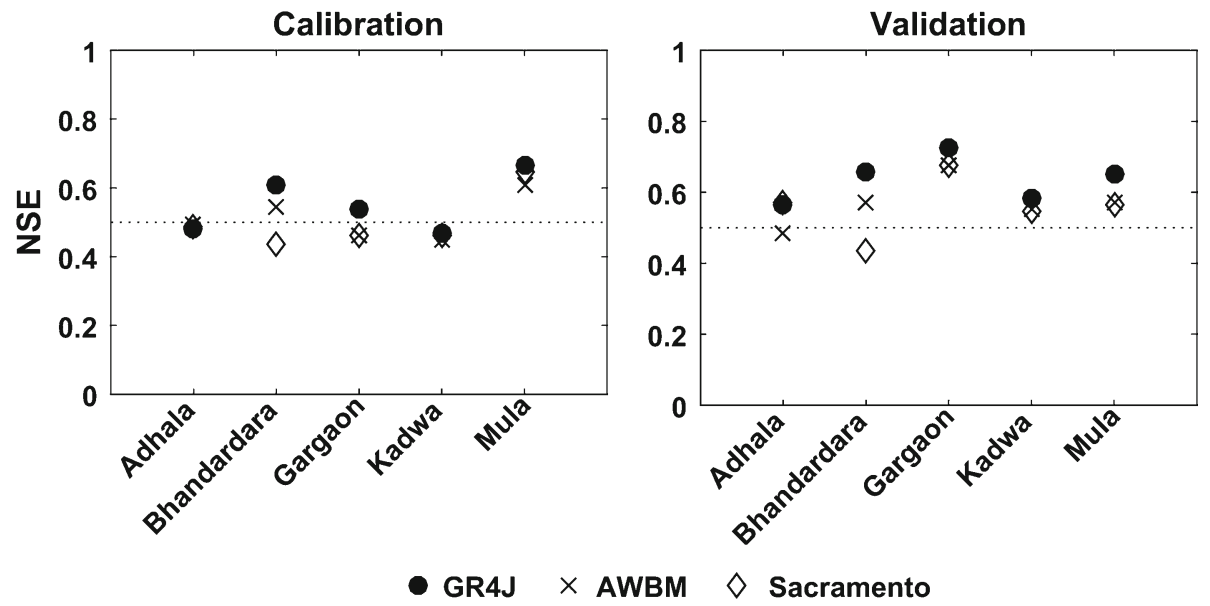

Figure 3. The comparison of streamflow NSE for the models GR4J, AWBM and Sacramento in the study catchments.

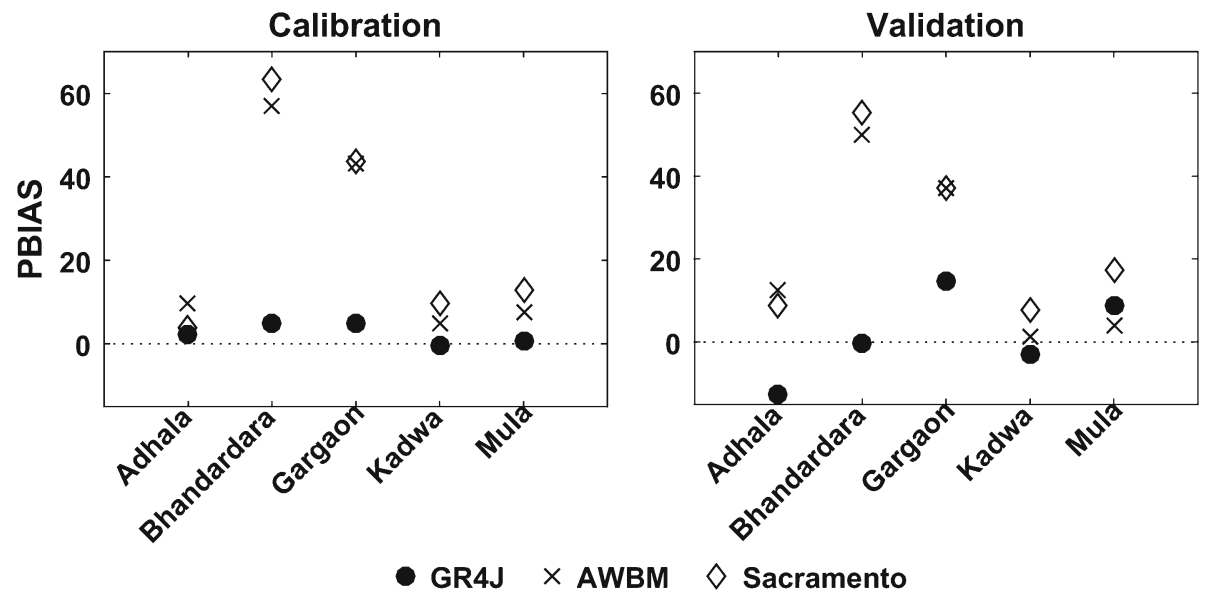

Figure 4. The comparison of streamflow PBIAS for the models GR4J, AWBM and Sacramento in the study catchments.
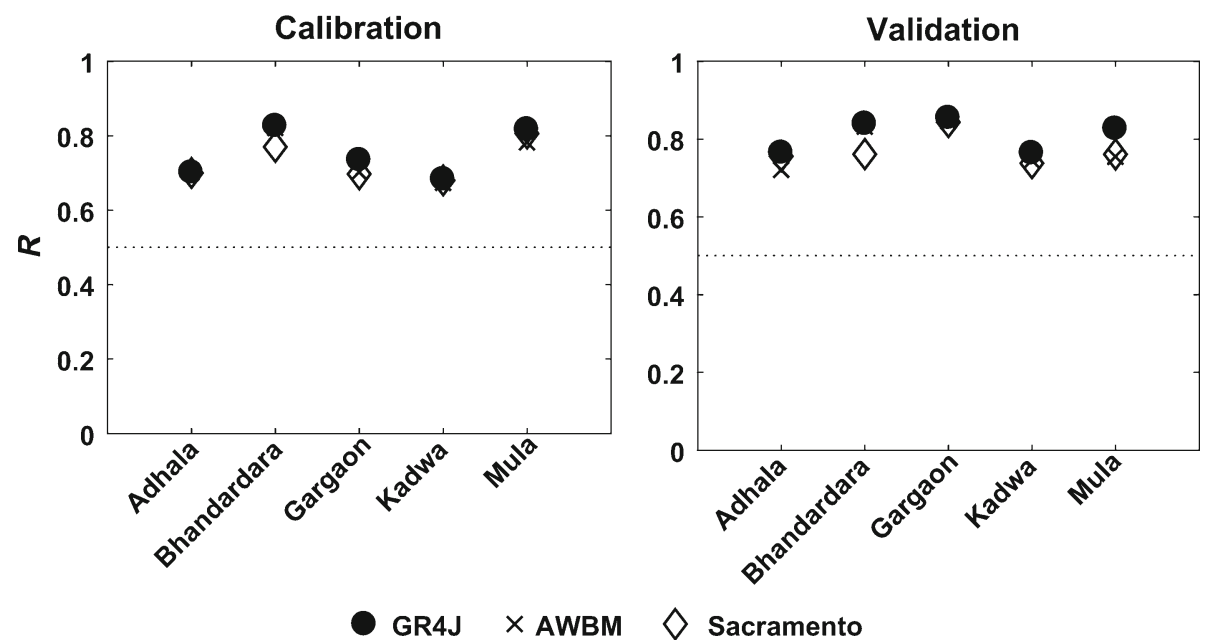

Figure 5. The comparison of $R$ of streamflow for the models GR4J, AWBM and Sacramento in the study catchments.

plotted in figure 6. These hydrographs help to identify the bias in the predictions and shifts in timing and magnitude of peak flows. Monthly time series of streamflow predictions for the study catchments for different models are given in figure 6. Streamflow peaks were matching well in both calibration and validation period without much time delay for all the catchments except 

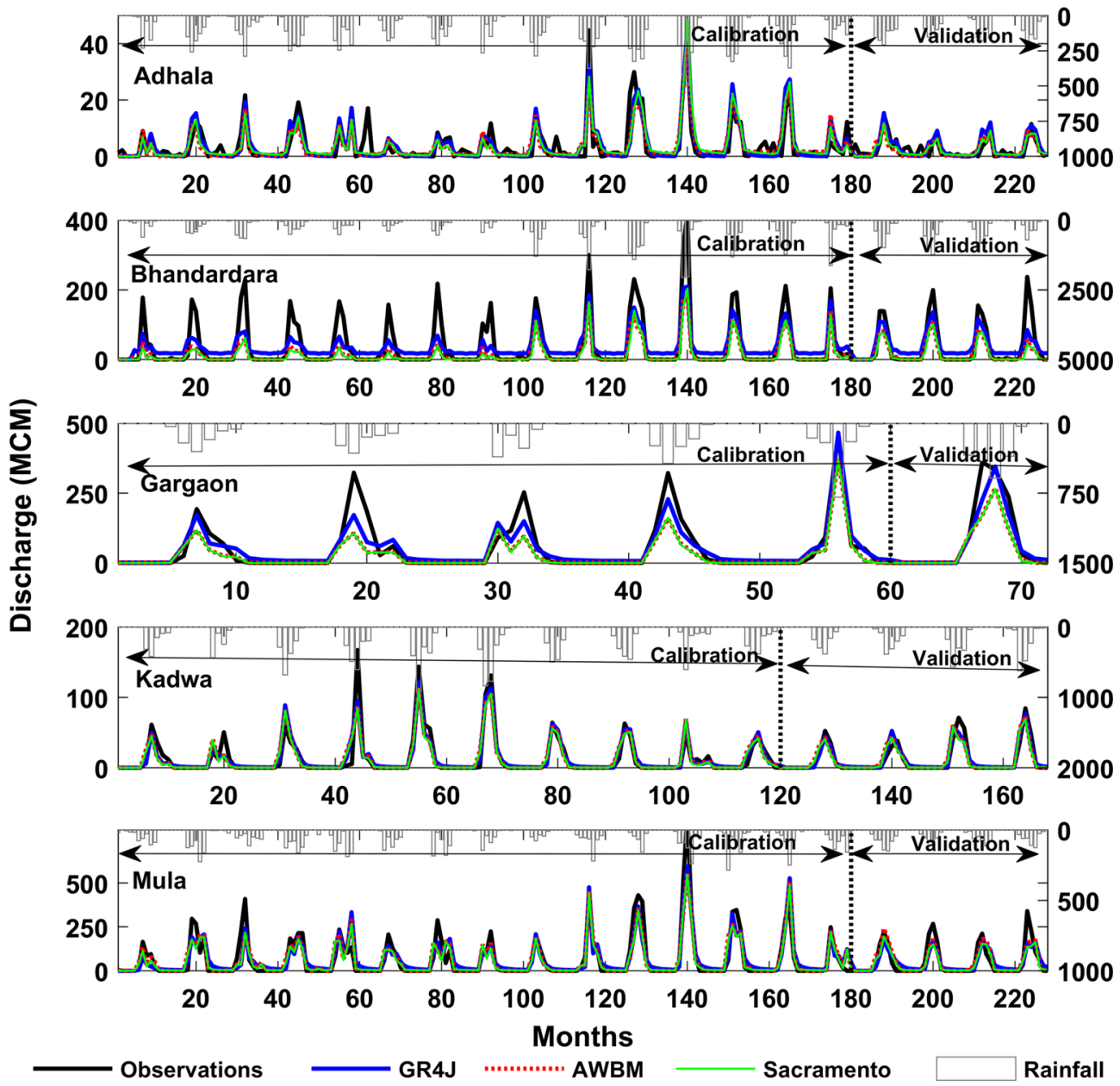

Figure 6. Time series of monthly streamflow predictions from GR4J, AWBM and Sacramento compared with observations at selected catchments.

Bhandardara. It was observed that in all the catchments GR4J was predicting the peaks better than AWBM and Sacramento. In most cases, the models were underestimating streamflow, which in turn provided positive value for PBIAS calculated in the numerical analysis.

In Bhandardara, the peaks were highly underestimated especially in the calibration period and GR4J captures peaks better than AWBM and Sacramento. No rain gauge stations are present inside Bhandardara catchment and the rainfall data of nearby catchments is used for estimating the rainfall using the Theissen polygon method. Since Bhandardhara is situated very near to the ridgeline, the rainfall must be higher than the nearby catchments, which are farther from the ridgeline. This underestimated rainfall can be a reason for the underestimation of streamflow.

Cumulative discharge curve was plotted for each model in all the catchments to understand the best-fit model to the observations (figure 7 ). Daily cumulated value of discharge was plotted against time. From this figure, it is noticed that GR4J fits well with observations in the catchments Adhala, Bhandardara and Gargaon. In Kadwa, GR4J fitted well in the calibration period; however, it was hard to choose one model during the validation. GR4J gave better fit during the calibration period for Mula catchment, but AWBM was superior during the validation period.

Percent exceedance probability curve, otherwise called as flow duration curve explains how well the model reproduces the observed flows during the calibration and validation period. This curve is plotted between the discharge and percentage of time that a particular discharge was equalled or exceeded. The flow duration curve plotted for all the study catchments is given in figure 8. In Adhala, all the three models gave similar exceedance probability for the calibration period and GR4J performs better in the validation period especially in the case of medium flows. 

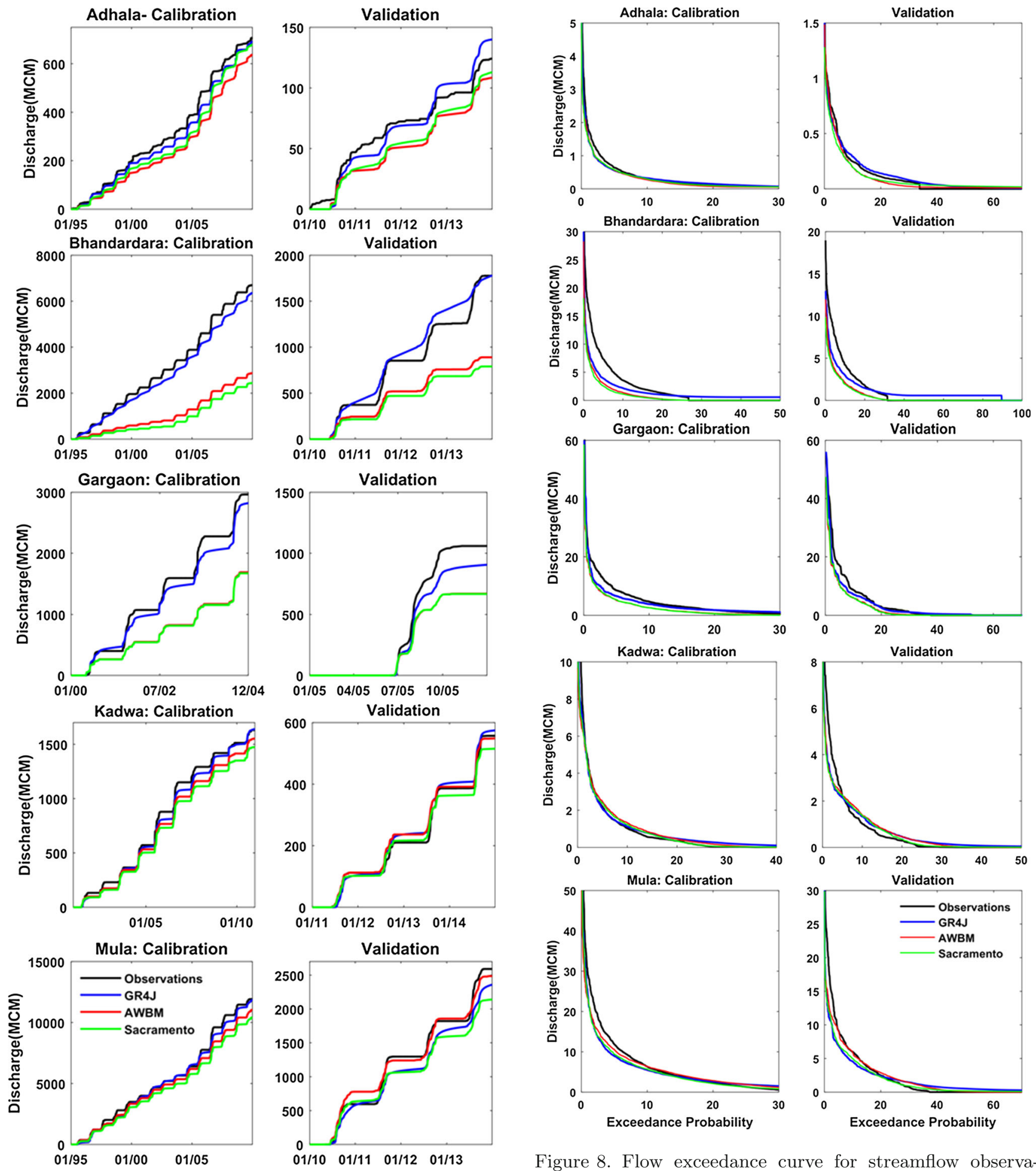

Figure 7. Cumulative daily streamflow predictions from GR4J, AWBM and Sacramento are compared with observations at selected catchments.

In Bhandardara, GR4J gave exceedance plot close to observations for high and medium flows and AWBM and Sacramento predict low flow frequency accurately. GR4J reproduces the observed flow well in the case of Gargaon. For Kadwa catchment, all
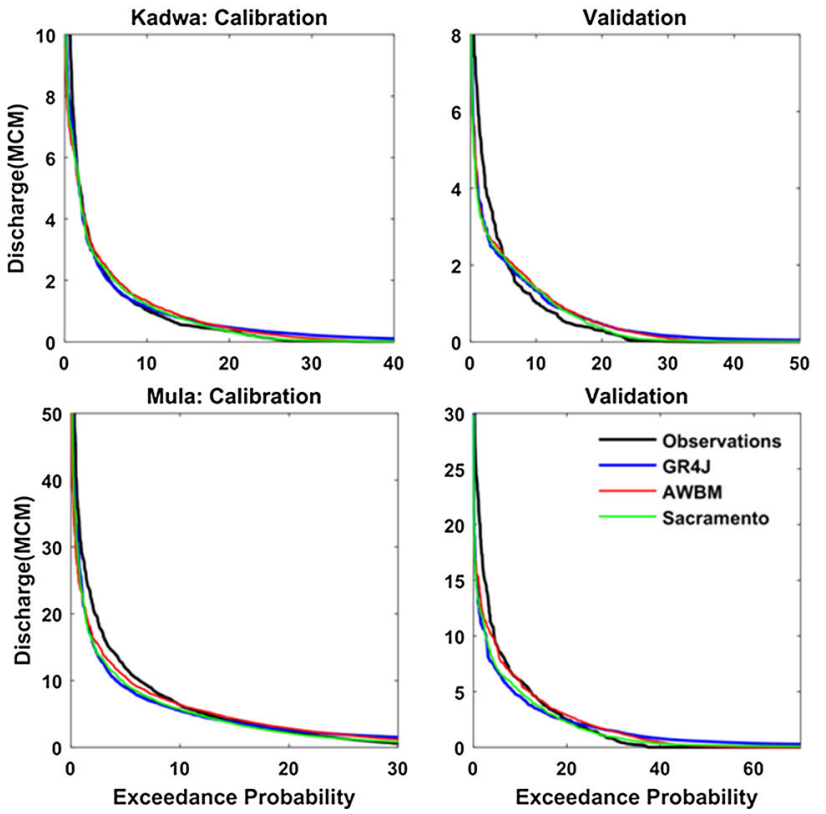

Figure 8. Flow exceedance curve for streamflow observations and predictions from GR4J, AWBM and Sacramento for both the calibration and validation period.

three models produce similar results. In the case of Mula, flow duration curve was better simulated by AWBM than GR4J.

The numerical and graphical analysis performed above implies that GR4J, AWBM and Sacramento 
are equally good for catchment modelling at the selected catchments. However, GR4J is recommended over the other models due to the following reasons:

(1) GR4J provided slightly better NSE, $R$ and PBIAS for most of the catchments during calibration and validation period.

(2) GR4J showed the best fit in cumulative discharge and exceedance probability graph except for Mula catchment.

(3) It was also noted that GR4J captures high flow events better than AWBM and Sacramento.

(4) GR4J is a simple two-store model compared to the five-store complex models AWBM and Sacramento.

(5) GR4J has only four parameters to optimise during the calibration, while AWBM has eight parameters and Sacramento has 22 parameters. The increment in a number of parameters during the calibration will increase the calibration time due to the time delay in convergence of parameters.

(6) Being a simple model, GR4J requires less time for calibration.

Except for Mula and Gargaon, all other study catchments are small catchments with an area of $<300 \mathrm{~km}^{2}$. Gargaon has an area of $616 \mathrm{~km}^{2}$. Mula is a medium-sized catchment with an area of $2300 \mathrm{~km}^{2}$. For Mula, it has been observed during the graphical analysis that AWBM was giving better results than GR4J, especially during the validation period. This is mainly due to the ability of AWBM to predict medium flows better than GR4J. For bigger catchments such as Mula, AWBM is also recommended.

\section{Discussion}

As seen in the case of GR4J, AWBM and Sacramento, the calibration of conceptual models is easy to carry out. However, in Indian basins, a model that simulates results based on distributed information is practised due to the heterogeneity in catchment topography and land uses (Gosain et al. 2006, 2011; Garg et al. 2013; Prabhanjan et al. 2014; Narsimlu et al. 2015). The literature reveals that distributed models such as VIC and SWAT are commonly used for hydrologic studies in the Godavari basin (Gosain et al. 2006; Uniyal et al. 2015; Hengade and Eldho 2016; Madhusoodhanan et al. 2017; Hengade et al. 2017). A study conducted in Tekra catchment of Godavari using VIC model received a daily NSE of 0.68 and monthly NSE of about 0.86 (Hengade and Eldho 2016; Hengade et al. 2017). In the study by Madhusoodhanan et al. (2017), the calibration at different catchments in Godavari provided monthly NSE of 0.7-0.9 using the VIC model. Similar efficiency is obtained in the present study also using the conceptual models GR4J, AWBM and Sacramento. A study by Aatish et al. (2018) concluded that GR4J performs better than SWAT model in Mula catchment, which is one of the catchments used in the present study.

Compared to distributed models, it is easy to interpret the results from the lumped rainfallrunoff models because of its simple structure. Lumped models treat the complete basin as a homogeneous system and estimate streamflow at the outlet node rather than calculating specific flows in the catchment. They simulate the average runoff inside the catchment satisfactorily at a high computational speed using catchment rainfall and PET as input. However, these models are inefficient to model the spatially distributed flow of the catchment for the changes in land use, topography and climate. Distributed or semi-distributed models such as VIC or SWAT, which require the land use and soil data as input will be a better choice for those studies. Streamflow is the major output from these conceptual models working in the Source platform. These models cannot be used for simulating other components of water balance such as soil moisture, baseflow, vegetation biomass, etc., as in distributed models.

Conceptual models are input-output-based models. During the calibration, these models tune the parameters according to match output best with observations. Therefore, the optimised values for parameter values obtained after calibration fall in different regions of parameter ranges for each catchment in most of the cases as seen in table 3 for GR4J and table 4 for AWBM.

The problem with rainfall-runoff model working in modelling interfaces such as Source has limited control for users on the model structure. The user can only define forcing data, parameter range and catchment properties. The model works as a blackbox model, without any control on model structure. Uncertainty in input data is another major issue to be dealt with in hydrologic modelling. For Bhandardara catchment, the rainfall data from adjacent stations is used to calculate the catchment rainfall 
Table 3. Optimised parameters for GR4J model.

\begin{tabular}{lrrrr}
\hline Catchments & \multicolumn{1}{c}{$x 1$} & \multicolumn{1}{c}{$x 2$} & $x 3$ & $x 4$ \\
\hline Adhala & 1.00 & -10.00 & 227.92 & 1.02 \\
Bhandardara & 1.00 & 5.00 & 14.34 & 1.08 \\
Gargaon & 1.00 & 5.00 & 85.98 & 1.13 \\
Kadwa & 18.72 & 2.56 & 276.16 & 1.20 \\
Mula & 26.02 & 2.23 & 182.02 & 0.97 \\
\hline
\end{tabular}

Table 4. Optimised parameters for AWBM model.

\begin{tabular}{lcccccrrr}
\hline Catchments & $A 1$ & $A 2$ & BF1 & $C 1$ & $C 2$ & $C 3$ & $K_{\text {base }}$ & $K_{\text {surf }}$ \\
\hline Adhala & 0.39 & 0.51 & 0.65 & 0.00 & 67.72 & 414.83 & 0.62 & 1.00 \\
Bhandardara & $7.510 \times \times^{-14}$ & $6.010 \times^{-16}$ & 0.08 & 0.00 & 16.39 & 0.00 & 0.00 & 0.27 \\
Gargaon & $1.110 \times \times^{-5}$ & $5.010 \times \times^{-8}$ & 0.80 & 0.00 & 0.00 & 0.00 & 0.46 & 0.82 \\
Kadwa & 0.10 & 0.75 & 0.47 & 0.00 & 0.00 & 148.86 & 0.70 & 0.70 \\
Mula & 0.01 & 0.38 & 0.50 & 0.00 & 84.37 & 0.00 & 0.89 & 0.48 \\
\hline
\end{tabular}

using the Theissen polygon method. The underestimated streamflow by the models illustrates that this can be due to an underestimated rainfall in that catchment. All the catchments in this study used ET data from nearby stations, which is also a source of uncertainty. A further study with these models should be performed to quantify the uncertainty in model structure and inputs on model predictions.

The main scope of conceptual models is in water resources management studies, where streamflow is the output of concern. Considering the simple structure, low data requirements and computational efficiency of conceptual models, they are being used in flood and drought forecasting, flood management, river basin management and reservoir management studies (Yang et al. 1995; Cameron et al. 1999; Yang and Michel 2000).

\section{Conclusions}

In this study, the performance of the models GR4J, AWBM and Sacramento was compared at five catchments in the upper Godavari basin. Conceptual models are gaining popularity among the different hydrological models used for catchment modelling due to their simple structure and satisfactory performance, worldwide. However, the choice of right model for water resource assessment in a particular region is a big challenge to hydrologists. Modelling platforms such as Source, by eWater, Australia, are reducing that challenge by integrating all the information for water resources management and modelling tools in one platform. This study was considered in finding the more appropriate conceptual model among GR4J, AWBM and Sacramento included in the Source framework.

Daily calibration is performed at Source calibration framework using NSE with bias penalty as the objective function. Based on the calibrations performed, the GR4J is suggested as the best model. It was noticed that GR4J captures high flow events better than Sacramento and AWBM. GR4J was slightly better in terms of NSE, PBIAS and correlation coefficient. Compared to AWBM and Sacramento, the GR4J is a simple two-store model and has only four parameters to optimise during the calibration, which in turn reduces the calibration time.

\section{Acknowledgements}

The authors would like to acknowledge the Water and Land Management Institute (WALMI), Aurangabad, the Godavari Marathwada Irrigation Development Corporation (GMIDC), Aurangabad and eWater, Australia, for providing necessary data for this study. The authors are thankful to WALMI and GMIDC for funding a project related to the present study. We gratefully thank suggestions of Dr Carl Daamen (eWater) and Dr Avinash Garudkar (WALMI) that have significantly improved this study. 


\section{References}

Aatish A, Eldho T I and Kunnath-Poovakka A 2018 Performance evaluation of SWAT with a conceptual rainfallrunoff model GR4J a catchment in upper Godavari river basin; In: International soil and water assessment tool conference, Chennai, January 2018, 101p.

Ajami N K, Gupta H, Wagener $\mathrm{T}$ and Sorooshian S 2004 Calibration of a semi-distributed hydrologic model for streamflow estimation along a river system; $J$. Hydrol. 298(1) 112-135.

Anderson R M, Koren V I and Reed S M 2006 Using SSURGO data to improve Sacramento model a priori parameter estimates; J. Hydrol. 320 103-116, https://doi. org/10.1016/j.jhydrol.2005.07.020.

Boughton W 2004 The Australian water balance model; Environ. Modell. Softw. 19 943-956.

Bumash R 1995 The NWS river forecast system-catchment modelling; In: Chapter 10, computer models of watershed hydrology (ed.) V J Singh, Water Resources Publications, Colorado, USA.

Burnash R, Ferral R and McGuire R 1973 A generalised streamflow simulation system - Conceptual modelling for digital computers; Joint Federal and State River Forecast Center, Sacramento, Technical Report.

Cameron D, Beven K J, Tawn J, Blazkova S and Naden P 1999 Flood frequency estimation by continuous simulation for a gauged upland catchment (with uncertainty); J. Hydrol. 219 169-187.

Carr R and Podger G 2012 eWater Source - Australia's next generation IWRM modelling platform; In: Hydrology and water resources symposium 2012, Engineers Australia, $742 \mathrm{p}$.

Chiew F, Peel M and Western A 2002 Application and testing of the simple rainfall-runoff model SIMHYD; Math. Models Small Watershed Hydrol. Appl., pp. 335-367.

Croke B F, Andrews F, Jakeman A J, Cuddy S M and Luddy A 2006 IHACRES Classic Plus: A redesign of the IHACRES rainfall-runoff model; Environ. Modell. Softw. 21 426-427.

Dutta D, Welsh W D, Vaze J, Kim S S and Nicholls D 2012 A comparative evaluation of short-term streamflow forecasting using time series analysis and rainfall-runoff models in eWater Source; Water Resour. Manag. 26 4397-4415.

Edijatno M C 1989 Un modeİe pluie-débit journalier àtrois paramétres; La Houille Blanche 2 113-121.

Edijatno M C, DeOliveira Nascimento N, Yang X, Makhlouf Z and Michel C 1999 GR3J: A daily watershed model with three free parameters; Hydrol. Sci. J. 44 263-277.

eWater Australia 2017 Source user guide 4.3; https://wiki. ewater.org.au.

Fowler K J A, Peel M C, Western A W, Zhang L and Peterson T J 2016 Simulating runoff under changing climatic conditions: Revisiting an apparent deficiency of conceptual rainfall-runoff models; Water Resour. Res. 52 1820-1846, https://doi.org/10.1002/2015WR018068.

Garg K K, Wani S P, Barron J, Karlberg L and Rockstrom J 2013 Up-scaling potential impacts on water flows from agricultural water interventions: Opportunities and tradeoffs in the Osman Sagar catchment, Musi sub-basin, India; Hydrol. Process. 27 3905-3921.
Gosain A, Rao S and Basuray D 2006 Climate change impact assessment on hydrology of Indian river basins; Curr. Sci. 99(3) 346-353.

Gosain A, Rao S and Arora A 2011 Climate change impact assessment of water resources of India; Curr. Sci. 101(3) 356-371.

Green C, Tomer M, Di Luzio M and Arnold J 2006 Hydrologic evaluation of the soil and water assessment tool for a large tile-drained watershed in Iowa; Trans. ASABE 49 413-422.

Gupta H V, Sorooshian S and Yapo P O 1999 Status of automatic calibration for hydrologic models: Comparison with multilevel expert calibration; J. Hydrol. Eng. 4 135143.

Hengade N and Eldho T 2016 Assessment of LULC and climate change on the hydrology of Ashti catchment, India using VIC model; J. Earth Syst. Sci. 125 1623-1634.

Hengade N, Eldho T and Subimal G 2017 Hydrological simulation of a large catchment using the variable infiltration capacity model; In: Development of water resources in India, Springer, pp. 19-30, https://doi.org/10.1007/ 978-3-319-55125-8_2

Jones R N, Chiew F H, Boughton W C and Zhang L 2006 Estimating the sensitivity of mean annual runoff to climate change using selected hydrological models; Adv. Water. Resour. 29 1419-1429.

Lavabre J, Torres D S and Cernesson F 1993 Changes in the hydrological response of a small Mediterranean basin a year after a wildfire; J. Hydrol. 142 273-299.

Lørup J K, Refsgaard J C and Mazvimavi D 1998 Assessing the effect of land use change on catchment runoff by combined use of statistical tests and hydrological modelling: Case studies from Zimbabwe; J. Hydrol. 205 147-163.

Madhusoodhanan C G, Sreeja K G and Eldho T I 2017 Assessment of uncertainties in global land cover products for hydro-climate modeling in India; Water Resour. Res. 53 1713-1734. https://doi.org/10.1002/ 2016WR020193.

Mannik R, Boronkay A, Jordan P, Church T, Hughes D and Blockwell S 2012 Applying eWater source as the catchment model for the Hawkesbury-Nepean water quality model system; In: Hydrology and water resources symposium 2012, Engineers Australia, 645p.

Moriasi D N, Arnold J G, Van Liew M W, Bingner R L, Harmel R D and Veith T L 2007 Model evaluation guidelines for systematic quantification of accuracy in watershed simulations; Trans. ASABE $\mathbf{5 0} 885-900$.

Narsimlu B, Gosain A K, Chahar B R, Singh S K and Srivastava P K 2015 SWAT model calibration and uncertainty analysis for streamflow prediction in the Kunwari River Basin, India, using sequential uncertainty fitting; Environ. Process. 2 79-95.

Nash J E and Sutcliffe J V 1970 River flow forecasting through conceptual models. Part I: A discussion of principles; J. Hydrol. 10 282-290.

Pechlivanidis I, Jackson B, Mcintyre $\mathrm{N}$ and Wheater $\mathrm{H}$ 2011 Catchment scale hydrological modelling: A review of model types, calibration approaches and uncertainty analysis methods in the context of recent developments in technology and applications; Global NEST J. 13.3 193214 . 
Perrin C, Michel C and Andréassian V 2003 Improvement of a parsimonious model for streamflow simulation; $J$. Hydrol. 279 275-289.

Prabhanjan A, Rao E and Eldho T 2014 Application of SWAT model and geospatial techniques for sediment-yield modeling in ungauged watersheds; J. Hydrol. Eng. 20 C6014005.

Rassam D, Jolly I and Pickett T 2011 Guidelines for modelling groundwater-surface water interactions in eWater Source, towards best practice model application; eWater. Interim. Version $\mathbf{1}$.

Redpath K and Daamen C 2018 Upper Godavari sub-basin baseline water balance model, technical report; eWater. Interim. Version 4.

Refsgaard J C 1997 Parameterisation, calibration and validation of distributed hydrological models; J. Hydrol. 198 69-97, https://doi.org/10.1016/S0022-1694(96)03329-X.

Şen Z 1998 Average areal precipitation by percentage weighted polygon method; J. Hydrol. Eng. 3(1) 69-72.

Sorooshian S, Hsu K-L, Coppola E, Tomassetti B, Verdecchia $\mathrm{M}$ and Visconti G (eds) 2008 Hydrological modelling and the water cycle: Coupling the atmospheric and hydrological models; Springer Heidelberg Berlin: California, vol. 63, $1-25$.

Uniyal B, Jha M K and Verma A K 2015 Assessing climate change impact on water balance components of a river basin using SWAT model; Water Resour. Manag. 29 4767-4785.

Viney N R, Perraud J-M, Vaze J, Chiew F H S, Post D A and Yang A 2009 The usefulness of bias constraints in model calibration for regionalisation to ungauged catchments; In:18th World IMACS congress and MODSIM09 international congress on modelling and simulation, July 2009, Cairns: Modelling and simulation society of Australia and New Zealand and International Association for Mathematics and Computers in Simulation, pp. 3421-3427.

Yang X and Michel C 2000 Flood forecasting with a watershed model: A new method of parameter updating; Hydrol. Sci. J. 45 537-546.

Yang X, Parent E, Michel C and Roche P-A 1995 Comparison of real-time reservoir-operation techniques; J. Water Res. Plan. Man. 121 345-351. 